\title{
Language Proficiency and Academic Success
}

Jennifer Hornbaker

\section{Introduction}

In 1988, linguists James P. Lantolf and William Frawley stated that, in the quest to characterize just what exactly is meant by language proficiency, "we are no closer to understanding the concept today than we were 20 years ago” (Lantolf \& Frawley, 1988, p. 185). Another quarter century has passed since Lantolf and Frawley's disheartening declaration, yet the question remains: How do we untangle the construct of proficiency? Although theoretical and empirical efforts over the years have attempted to identify the components of proficiency, anything resembling a consensus has yet to be reached. With more than four decades devoted to delineating this seemingly simple idea, doubt emerges as to whether a single definition indeed exists that can satisfy the factions of professionals in the second language acquisition field. However, recent paths of thought have trod in a promising direction. Researchers are painting a more sophisticated picture of proficiency through the application of measurable linguistic features to traditionally subjective competency descriptions. As this linguistic quantification process continues, we can begin to examine how a deeper, more precise understanding of proficiency can inform the curriculum and assessments that determine student readiness to enter university study. Thus, this paper serves two purposes. First, it reviews historical and contemporary interpretations of proficiency and, in doing so, outlines the measurement strategies in use in the realm of English for academic purposes. Second, it crosses the bridge from English proficiency testing to university academia, analyzing the factors in play in student academic readiness and the role of language proficiency in student success.

\section{What is Language Proficiency?}

The term "proficiency" itself intimates a black-and-white, reductionist view of language ability; the language user is either proficient or deficient (Harper, Prentice, \& Wilson, 2011). However, just as language learners possess varying levels of linguistic capabilities, so, too, do native speakers. Taking into account the different knowledge levels and styles of both native and non-native speakers, it seems impossible to pigeonhole language proficiency into a single denotation (Hulstijn, 2007). Despite this quandary, a rich history of language proficiency exploration has presented a number of explanations for the concept.

\section{Defining the Construct}

According to the well-established definition by Canale and Swain (1980), proficiency encompasses competence, or knowledge of the underlying production of and interpretation of language, and performance, or the actual comprehension and generation realized by the interlocutor. This distinction suggests a communicative paradigm in which interlocutors must not only know about but also know how to use a language. More explicitly, Canale and Swain proposed three subsets of linguistic proficiency: (1) grammatical competence, or knowledge of the phonological, morphological, lexical, syntactical, and semantic properties of a language; (2) sociolinguistic competence, or knowledge of the appropriateness of language functions given situational factors such as topic, participants, setting, and norms; and (3) strategic competence, or knowledge of the communication techniques, verbal and nonverbal, that serve to negotiate and repair communication breakdowns. Since this demarcation of proficiency, many elaborations have followed. What these various 
positions hold in common is a partitioning of the construct. Bachman (1990) adjusted Canale and Swain's model, suggesting the whole of language ability is made up of 1) language competence, or knowledge of language; 2) strategic competence, or the mental capacity to implement language knowledge in context; and 3) psychophysiological mechanisms, referring to the neurological and psychological processes involved in physically producing language. De Jong (2004) dichotomized proficiency into language quantity, referring to what the user is able to do, including the domains, functions, topics, and roles the user can negotiate, and quality, how well the user is able to perform, or the degree to which the language use is effective in its precision of meaning. Hulstijn (2007) suggested an existence of basic and higher levels of language cognition, with a core component representing the implicit, automatic language attainable by most adults and a peripheral component representing a higher order of language cognition that requires both conscious awareness of language processing, e.g. explicit knowledge of vocabulary, as well as subconscious processes such as attention allocation and inferencing skills.

The division of language proficiency into lower and higher orders is a common thread in proficiency analyses in academic settings in particular. The distinction between social and academic language gained wide recognition with Cummins' (1980) BICS (basic interpersonal communication skills) vs. CALP (cognitive academic language proficiency) model. Northedge (2003), Macken-Horarik, Devereux, Trimingham-Jack, and Wilson (2006), and Murray (2010) echoed Cummins by partitioning language into everyday, academic, and professional literacies. With a hierarchical separation of language skills constituting the unifying theme throughout these various theories of proficiency, one impression seems clear; proficiency, despite its all-ornothing tone, in reality is more accurately captured by the term development, indicating gradual growth over time. Both native and non-native speakers develop knowledge of and skills in the linguistic contexts in which they participate. This truth is particularly evident in a university setting, where both native speakers and language learners develop their linguistic framework to meet the demands of new academic and professional environments.

Turning the focus to the realm of academia, then, a number of complications arise in assessing proficiency. It has been the challenge of institutions worldwide to determine exactly where to draw the line on the “acceptable" level of proficiency required for engaging in academic and professional endeavors. In attempting to draw this line, we may consider the following questions: (1) How can underlying linguistic knowledge be assessed if it is only displayed through the learner's performance? (2) Does underlying knowledge even matter in assessment if, due to language's interactional nature, only performance can be manifested in the communication process? (3) Finally, if both native and non-native students undergo linguistic growth throughout their academic experiences, what level of linguistic proficiency is "enough" to allow language learners to keep pace with their native-speaking peers in attaining academic success?

\section{Measuring Language Proficiency}

Even though attempts at proficiency characterization have posed more questions than answers, the sheer number of English language learners aiming to study at English-speaking universities demands some sort of assessment to gauge a student's academic potential in English (Hulstijn, 2007). English language proficiency tests date back a full century to the Certificate of Proficiency in English, introduced in 1913 by the University of Cambridge Local Examinations Syndicate to ensure incoming students met the school's standard of English

Back to Table of Contents 
competency before university entrance (Taylor \& Geranpayeh, 2011). Since then, multiple tests and proficiency descriptors have been developed to determine ELLs' readiness to succeed in English academics, some of the most widely used being the TOEFL and IELTS tests and the ACTFL Guidelines. The dilemma in this backwards scenario of assessing English proficiency without clarifying exactly what proficiency entails, though, is that proficiency becomes whatever the tests measure. That is, the situation becomes an instance of "the tail wagging the dog” (Lantolf \& Frawley, 1988, p. 182). This realization suggests that the what and how of proficiency test measurements and descriptors have serious implications for framing the meaning of language proficiency, not to mention the futures of the test takers. Nonetheless, empirically based models of second language acquisition find little place in the determination of proficiency levels by these measures. For instance, the ACTFL proficiency guidelines state that "the Guidelines are not based on any particular theory” (ACTFL, 2012, p. 3).

This dearth of theoretical and empirical backing results in proficiency descriptors that are vague and subjectively based. For instance, a student earning a three out of four for speech delivery on the TOEFL iBT produces speech that is "generally clear, with some fluidity of expression, though minor difficulties with pronunciation, intonation, or pacing are noticeable and may require listener effort at times" (Educational Testing Service, 2004, p. 1). Likewise, a writer testing into the sixth of nine band levels for grammatical range and accuracy on the IELTS writing task 1 test "makes some errors in grammar and punctuation but they rarely reduce communication” (IELTS Partners, 2009, p. 1). According to the ACTFL Guidelines, an intermediate high reader is "able to understand fully and with ease short, non-complex texts that convey basic information and deal with personal and social topics to which the reader brings personal interest or knowledge” (ACTFL, 2012, p. 23).

Certainly, it can be argued that subjective interpretation is the measuring stick of communication in the real world; inherent in language is the human factor in its employment. In fact, in an examination of the consistency of teacher judgments of English proficiency over time, Llosa (2011) observed that teachers were good judges of overall language ability despite a demonstrated inability to consistently interpret students' performances on individual standards. Considering the high stakes resting on the appraisal of a student's language proficiency, though, uncovering more objectively measureable linguistic features to anchor subjective judgments seems much more palatable. That is, rather than cloudy assertions such as "writers...show evidence of control of basic sentence structure and verb forms” (ACTFL 2012, p. 13), in which the subtleties of a student's performance are at the mercy of an evaluator, defining why a learner has "control of basic sentence structure” would make such descriptors more accurate and also more meaningful in informing language curriculum.

The obvious complexity of this task speaks to why current proficiency measures do not attempt to delve deeper into the facets of linguistic competence. Since Bailey, Madden, and Krashen (1974) proposed that learners follow a predictable path of language acquisition, additional studies have followed suit in identifying stages of language development (Hawkins, 2001). However, the variables and variations in results among studies form shaky grounds from which to assert that the route is identical for all learners (Hulstijn, 2007). Thus, the hesitancy of test makers to adopt such linguistic foundations to define proficiency levels is understandable. Still, the result of this reluctance is that proficiency guidelines are a "haphazard collection of descriptors" that are "strikingly random” in describing how linguistic features contribute to overall proficiency (Levis, 2006, p. 245). Such a predicament led Hulstijn (2007) to declare that "it is high time that researchers of SLA, researchers of 
language assessment, and corpus linguists paid attention to each other's work and engaged in collaborative research, testing the linguistic, psycholinguistic, and sociolinguistic assumptions” on which proficiency measures rest (p. 666).

Although, as yet, no definition of language proficiency independent from the tests themselves exists, the field is making headway. In recent years, there have been a number of attempts to identify objective, concrete linguistic measures that correlate with subjective guidelines. Such attempts are outlined in the sections that follow for five language skills: writing, speaking, grammar, reading, and listening.

Writing. As a productive skill, writing poses a challenge in proficiency assessment in that not all facets of a learner's competence may be displayed on any one test. Even so, informed evaluations can be made using quantifiable writing dimensions. Based on a meta-analysis of L2 writing studies, Wolfe-Quintero, Inagaki, and Kim (1998) outlined a three-pronged approach to measuring writing development: fluency, or the ability to write more in a designated amount of time; accuracy, or the absence of errors in writing, and complexity, or the intricacy of grammatical and lexical structures in writing. They determined that, in terms of fluency, three measures, namely words/T-unit (T-unit = main clause + subordinates), error-free T-unit length, and clause length proved to be the best predictors of writing proficiency across studies, forming a linear relationship with L2 writing ability.

Regarding accuracy, Wolfe-Quintero et al. (1998) found the relationship between accuracy measures (e.g. errorfree T-units, error-free T-units/T-unit, and errors/T-unit) and proficiency as defined by program level to be unclear; four studies revealed a linear relationship — that is, decreased errors with increasing proficiency-while six did not, perhaps reflecting a trade-off between accuracy and complexity as more advanced learners sacrifice accuracy in their attempts at more complex sentences. However, studies that used holistic teacher ratings of proficiency across multiple proficiency levels or within a narrow range of test scores did show a consistent linear progression of accuracy with proficiency. The strong correlation between errors and holistic ratings suggests that errors are particularly salient to teachers when they are making writing performance judgments.

With respect to complexity, grammatical complexity was best determined by number of clauses/T-unit, but dependent clauses/T-unit and measures of passives, articles, relative clauses, and complex nominals were also successful in differentiating developmental level. Lexical variation and sophistication but not density-the proportion of lexical words to total (lexical + function) words-appeared to be related to lexical complexity. Specifically, a word type variation measure developed by Carroll (1967) (total number of different word types/square root of two times the total number of words used) served as the strongest variation measure because the formula accounts for composition length; employing a seemingly more intuitive formula, i.e. word types/total words, incidentally penalizes longer compositions, as their length inevitably leads to repeated word types. Finally, word sophistication, as measured by total number of sophisticated word types/total number of word types, was also a valuable gauge of lexical complexity.

Other studies focusing on lexicon have found that human judgments of lexical proficiency are best predicted by a text's lexical diversity, word frequency, and conceptual levels of the word, such as word familiarity and imagability, or the ease with which a visual representation of a word can be accessed (e.g. "dog” with high imagability versus “insight” with low imagability). In a corpus of writing samples produced by ELLs at American universities, these three factors alone correctly classified 70 percent of texts into proficiency levels, 
as determined by TOEFL and ACT ESL Compass scores (Crossley, Salsbury, \& McNamara, 2011). Notably, Crossley and McNamara (2012) observed that cohesiveness was unimportant in differentiating between highly proficient and lower-rated L2 writers in a Hong Kong high school, perhaps because one primary measure of cohesiveness is word overlap, which intuitively relates inversely to lexical diversity. Instead, linguistic sophistication, including word frequency and specificity, appeared to be a marker of more advanced English writing proficiency. Thus, the three linguistic features of lexical diversity, word frequency, and conceptual word levels seem to be “tentacles to the writers' language abilities" (Crossley \& McNamara, 2012, p. 116).

Speaking. The area of L2 speaking has also seen new efforts to create comprehensibility guidelines that correlate quantitative measures of phonology, fluency, and discourse with native listener judgments of comprehensibility. In a study with French learners of English, Isaacs and Trofimovich (2012) used 19 linguistic measures in areas such as phonological and grammatical accuracy, lexical richness, and story cohesion to develop data-driven descriptors of learner proficiency levels. They found accuracy of English word stress to most strongly distinguish among high, intermediate, and low comprehensibility, although this finding might be tied to the L1, French, in which word stress is noncontrastive. Iwashita, Brown, McNamara, and O'Hagan (2008) conducted a similar study with 200 L2 English speakers of varied linguistic backgrounds and demonstrated that aspects of vocabulary, grammatical accuracy, fluency (speech rate), and pronunciation distinguished among holistically rated proficiency levels, with vocabulary and fluency being especially impactful. That some speaking elements held more weight in native listener ratings supported Higgs and Clifford's (1982) claim that not all aspects of speaking are equally important in speaking skill development. The findings of De Jong, Steinel, Florijn, Schoonen, and Hulstijn (2012), too, support this position. In a study testing speaking proficiency across tasks of varying complexity, formality, and discourse type, the researchers showed seven linguistic skills to be associated with functional adequacy of speech: (1) use of vocabulary, (2) use of grammar, (3) speed of lexical retrieval, (4) speed of sentence building, (5) sound quality of pronunciation, (6) word stress, and (7) intonation. Of these factors, vocabulary and intonation alone explained 75 percent of the variance in speech proficiency. The results of these investigations lay the groundwork for future research to establish a weighting system of linguistic skills in speaking assessment and curriculum.

Grammar. Many proficiency measures, e.g. the TOEFL, use impressionistic rating terms such as "basic," "moderate," and "good" in the assessment of grammar use. In order to qualify such terms, Young-Scholten and Ijiun (2006) applied the theory of organic grammar to writing samples produced by ELLs at an American community college to predict advancement in proficiency level. The organic grammar theory asserts that a learner follows a predictable route in language acquisition, developing from a base stage of L1-like syntax and nonfinite verbal morphology to an end state resembling the target language (Vainikka \& Young-Scholten, 2006). The organic grammar criteria did accurately predict student progression, even more so than impressionistic ratings.

In a separate attempt to apply concrete grammatical development indicators to ambiguous rubrics, Spinner (2011) applied the organic grammar theory as well as processability theory (Pienemann, 1998, 2005) to spontaneous ELL production data. Like organic grammar, processability theory outlines a predictable path of language acquisition based on stages of morphosyntactic development (Pienemann, 1998, 2005). Spinner's results showed that the developmental sequence laid out by processability theory did predict the order of morphosyntactic feature emergence. For example, word order, plurals, regular past tense, and possessive 
pronouns emerged in production before sentences beginning with a nonsubject, object pronouns, third-person singular, and wh- complement phrases. However, in contrast to Young-Scholten and Ijuin's results, the progression outlined by organic grammar theory did not adequately describe learners' morphosyntactic development; some students reached higher levels on the organic grammar scale without demonstrating evidence of lower stages. Despite inconsistent findings and complications stemming from L1 and writing/speaking task differences, these studies paved the way for future research to pursue a unified mechanism for more precise grammatical evaluation.

Reading. Because reading is a receptive skill, test design can more easily control what skills are assessed. This characteristic, however, also positions the test itself as a larger confounding factor in reading proficiency appraisal; student comprehension can only be measured through the dimensions comprising the test. This predetermination of the skills on display makes extracting specific developmental landmarks from holistic reading measures more difficult.

Garcia Gomez, Noah, Schedl, Wright, and Yolkut (2007) illustrated this issue in a report on the creation of the descriptors for the iBT version of the TOEFL reading test: "The goal was to provide descriptive information about the abilities that test takers need in order to answer questions correctly” (p. 417). The wording of this statement - that the descriptors define abilities for test-taking success and not reading success-reflects the interdependence of the test rubrics and the characterization of proficiency.

Nevertheless, the TOEFL iBT reading test descriptors do represent two abilities that are widely recognized as cornerstones of reading proficiency: (1) basic comprehension, defined as lexical, syntactic, and semantic abilities that allow information presented in single sentences and across sentences to be understood, and (2) reading to learn, which requires students to identify the organization and purpose of a text, distinguish major from minor details and essential from nonessential information, and understand rhetorical functions like cause and effect. Likewise, other language tests reflect a similar approach to reading proficiency measurement. For example, the English as a Second Language Placement Exam (ESLPE) at UCLA defines reading ability as the sum of two subskills: understanding explicitly stated information and understanding implicitly stated information.

As vocabulary is quite clearly instrumental to reading comprehension, many studies have examined the utility of vocabulary measures in predicting reading proficiency. Most researchers agree that breadth and depth are two scopes that serve as a lens into students’ vocabulary knowledge (Qian \& Schedl, 2004). To the list of vocabulary knowledge components, others have added lexicon organization and processes of lexical access (Chapelle, 1998), precision of meaning and receptive and productive knowledge (Henriksen, 1999), and form, position, and function (Nation, 2001). Considering this previous research, Qian and Schedl (2004) compiled a model of vocabulary knowledge that includes size, depth, organization, and automaticity of receptiveproductive knowledge. They used this model to test the relationship between vocabulary and reading comprehension in international students at an IEP in Canada. Findings indicated that vocabulary depth and basic reading comprehension were highly correlated. Zareva, Schwanenflugel, and Nikolova (2005) also found that vocabulary size, knowledge of less frequent as well as highly frequent words, and number of associations distinguished well between advanced and intermediate learners. Thus, vocabulary tests hold promise in measuring not only vocabulary knowledge but also reading skills. 
Listening. In the broad scope of language acquisition research, the number of studies exploring the listening proficiency construct pales in comparison to the body of information focusing on the other skill sets. However, the development of the listening section of the ESLPE at UCLA, as discussed by Song (2008), provides an interpretation of listening competence. Song posited that three subskills, closely resembling the reading models reviewed previously, constitute listening proficiency: understanding main and topical ideas, understanding details, and making inferences. A subsequent study in 2011 suggested that note-taking quality indicates listening proficiency equally as well as open-ended measures. Number of topical ideas taken down and organizational schema of notes were especially useful in predicting listening proficiency. Furthermore, Song found that, as might be expected, topics recorded in notes measured student understanding of topical ideas, and number of details included in notes measured student understanding of details. Interestingly, note organization was a strong indicator of inferencing ability. These associations were stronger when a skeleton outline was provided for students in comparison to note-taking from a blank slate, suggesting that an outline format facilitates students in taking complete notes at every level of information. This finding proves valuable seeing that many academic courses in today's universities offer lecture outlines or slides for student use.

Long, Gor, and Jackson (2012) took the first step toward matching developmental linguistic features to both speaking and listening, using perceptive and productive tasks with L1 English-L2 Russian learners. Regarding perceptive tasks, they found that variables relating to phonology, imperative constructions, approximate versus exact numerals, and collocations distinguished among levels 2, 2+, and 3 on the Interagency Language Roundtable (ILR) scale; some grammatical measures (verbal adverbs, derivational morphology, participles, reflexive verbs, and basic lexicon nouns), however, only differentiated levels 2 and 2+, while derivational morphology, semantics, subjectless sentence constructions, verbal prefixes, and indefinite nouns discriminated between ILR 2+ and 3 but not 2 and 2+. The fact that the perception tests that best classified learner proficiency varied according to the levels being distinguished is particularly interesting and underscores the significance of fine grammatical details in describing learners' language progression.

Limitations. In synthesizing the body of information presented here, an obvious question regards the effect of the L1 on the emergence pattern of linguistic features. That is, is the particular path of speaking, listening, reading, writing, and grammatical development—and thus the linguistic features that can be used to distinguish among proficiency levels in each skill area-affected or determined by the L1, and, if so, how? Another concern is the authenticity of test tasks. Bachman (1991) maintained that the language abilities measured by a language test should parallel the language abilities involved in non-test language use. Therefore, the characteristics of test tasks should correspond to features of target language use in context (Bachman, 1991). Professional perspectives in the TESOL field in general align with Bachman's outlook, strongly promoting language use in lifelike contexts. English for academic purposes, though, puts a twist on the matter; many of the activities that form the academic experience, such as writing papers, do not reflect real-life situations for most professions. In fact, school itself is a rather inauthentic experience much of the time. Therefore, in EAP test development and curriculum design, is the "reality" for which students are to be prepared the reality of university or the world beyond?

Regardless of L1 influence and test task authenticity, the most substantial problem with these studies is that most use the very measures that have been identified as flawed-TOEFL, IELTS, and ACTFL measures—as the standard against which to compare empirical backing for rater intuitions. Relying on vague measurements 
that are themselves in want of theoretical and empirical backing as baselines in turn compromises the efficacy of new research in escaping the pitfalls of current proficiency assessment methods.

\section{Other Factors Correlated with Proficiency}

Despite the current focus on mapping the linguistic path undertaken by language learners, it is important to note that L2 proficiency is not isolated from the L1 or even non-linguistic variables; other factors have been shown to contribute to second language competency. Such factors include L1 dexterity, aptitude for language learning, affective characteristics, cognitive skills, and educational background.

Native language and aptitude for language learning contribute in no small way to foreign language proficiency. Carroll and Sapon (2000) outlined the construct of aptitude as the aggregate of phonemic coding ability, grammatical sensitivity, associative memory, and inductive language learning ability. These elements are manifested through both the L1 and the L2, with aptitude for language learning in general relating to skillful use of both native and foreign language to accomplish communication goals (Sparks \& Ganschow, 1991, 1995). Specifically, early L1 skills, namely word decoding, spelling, vocabulary, and reading and listening comprehension, have been shown to connect to both L2 aptitude and L2 proficiency later in life (Sparks, Humnbach, \& Javorsky, 2008; Sparks, Patton, Ganschow, \& Humbach, 2009). For instance, Sparks, Patton, Ganschow, Humbach, and Javorsky (2006) found that L1 skills in grades one through five explained 73 percent of the variance in students' L2 aptitude in grade nine, and early L1 reading skills alone accounted for 40 percent of the variance in oral and written L2 proficiency. In line with this trend, Rysiewicz (2008) found native vocabulary inventory to be the most differentiating variable in foreign language learning success, and Ito (2004) observed L1 writing skills to be a more powerful predictor of L2 writing than L2 knowledge in general.

In later studies, Sparks and colleagues calculated that L1 phonological and orthographical skills explained 26 percent of the variance in total L2 proficiency, while self-perceptions of language skills and language analysis accounted for 20 percent and 16 percent of L2 proficiency variance (Sparks, Patton, Ganschow, \& Humbach, 2011). Notably, in an American high school, students with low levels of foreign language proficiency did not necessarily possess weak L1 skills; many low proficient learners demonstrated average L1 word decoding, phonological awareness, vocabulary use, and reading comprehension. It was the highly proficient language learners who differentiated themselves with exceptional L1 skills and aptitude (Sparks, Artzer, Ganschow, Siebenhar, Plageman, \& Patton, 1998).

These trends do not always seem to be consistent across language groups, however. For instance, Englishlearning native speakers of Japanese and Arabic but not native speakers of Chinese and Hebrew showed a significant correlation between L1 and L2 writing abilities, although differing proficiency levels among the learners tested complicated these results (Abu-Akel, 1997; Carson, Carrell, Silberstein, Kroll, \& Kuehn, 1990). Nevertheless, it can be concluded that, by and large, L2 proficiency seems to be closely related to deftness in the L1, and L2 aptitude tests appear to provide reliable predictions of L2 proficiency (Sparks, Patton, \& Ganschow, 2012).

Affective variables also appear to influence proficiency. Masgoret and Gardner (2003) conducted a metaanalysis of attitudinal factors involved in second language achievement and calculated that openness to identify with the language community, motivation, and attitude toward the learning situation all formed positive correlations with language achievement, with motivation accounting for the most variance (8-16 percent) in the

Back to Table of Contents 
majority of studies. Neither availability of the language in the community nor age held moderating effects on these relationships.

Language learning anxiety is another factor posited to affect L2 learning, although researchers disagree on its status as an impediment or a side effect. MacIntyre (2002) backed the camp supporting language learning anxiety as a causal element in L2 achievement. In contrast, Sparks and Ganschow proposed that low motivation and language learning anxiety are effects of, rather than causes of, lower language skills and aptitude (Sparks \& Ganschow, 1996; Ganschow, Sparks, Anderson, Javorksy, Skinner, and Patton, 1994).

A number of cognitive skills have also been linked to language proficiency. Notably, L2 success does not seem to depend on rote memory. Rochecouste, Oliver, and Mulligan (2012) found that language-learning approaches involving rote learning had a negative impact on language growth and academic achievement. In an examination of 13-year-old ELLs in Poland, rote memory was not shown to either impede or enhance foreign language learning. Rather, analytical language abilities appeared to contribute to language learning success, with low language induction abilities proving to be detrimental to L2 proficiency (Rysiewicz, 2008). Results from a study conducted by Harley and Hart (2002) somewhat supported this trend; analytical language ability was found to be predictive of L2 success in late immersion learners, although memory better predicted L2 success in early immersion learners.

Intuitively, one might also presume that discipline-related knowledge could facilitate the acquisition of a foreign language in that content area. Indeed, an interaction between discipline-related knowledge and proficiency was found in Usó-Juan’s (2006) investigation of native Spanish-speaking ELL undergraduates, with field knowledge accounting for 21 to 31 percent of EAP reading scores and 58 to 68 percent of proficiency in general. A lack of discipline-related knowledge could be compensated for with higher language proficiency, but learners needed at least an intermediate level of L2 language to do so. Conversely, a lack of proficiency could be counterbalanced to a certain extent with discipline-related knowledge. East Asian graduate students studying in the U.S. corroborated Usó-Juan's findings, stating that familiarity with the academic language and body of research in their areas of study helped them attain academic success in the L2 (Ren, Bryan, Min, \& Wei, 2007). In summary, the linguistic threshold required for academic success seems to see-saw based on the interaction between discipline-related knowledge and language proficiency, allowing for lower proficiency in the presence of higher background knowledge.

\section{Student Academic Success}

The manifold dimensions of language proficiency substantiate the difficulties of pinning down a precise definition of the construct. Despite a want of firm footing on exactly what language proficiency is, though, its ties to academic success are well documented. Lack of English proficiency is the primary obstacle for nonnative-speaking international students undertaking studies at English-speaking universities (Mori, 2000; Selvadurai, 1998). Even for international students who have participated in years of English study at home, transitioning from study of English to study in English proves challenging (Johnson, 2008). In order to best prepare ELL students to achieve their academic ambitions, identifying which aspects of language proficiency affect academic success and in what ways seems integral to establishing best practices in program structure, curriculum, and test design in both IEPs and universities as a whole. 
As with language proficiency, academic success has many interpretations across contexts. Implicit to the word success is the recognition of a goal that has been accomplished. That goal obviously differs among students, but it can be reasonably assumed that earning a degree would merit the label of "success.” However, smaller mileposts along the way also serve as useful indicators of success, particularly in analyses taking place in shorter timeframes, such as a semester or academic year. These mileposts include progress toward degree or credit completion, GPA, and even students' personally rated progress toward goals. The purpose of these markers is to provide some sort of "evidence of learning" on the road to attaining the ultimate goal, degree completion (Snow Andrade, 2006, p. 134). Thus, while true "success” might not be fully realized until a diploma is received, these achievement-oriented measures of short-term success serve as in-progress projections of eventual academic success. Therefore, while some may differentiate between academic achievement (e.g. GPA) and academic success (e.g. degree completion), in the context of this paper, the two terms will be used interchangeably.

\section{Linguistic Factors in Academic Success}

At first glance, the relationship between language proficiency and academic success appears to be weak. A number of studies were unable to find clear evidence linking the two concepts (Graham, 1987; Neal, 1998; Person, 2002). Backed by Isonio’s (1994) findings that international students perform as well as or even better than their American counterparts, it seems that the common-sense stance-that language proficiency lies central to achieving academic success in that language-may not hold true.

Notwithstanding this tepidity, a wealth of studies provides modest but significant evidence that language proficiency correlates positively with academic success (Ayers \& Peters, 1977; Bayliss \& Raymond, 2004; Dooey \& Oliver, 2002; Feast, 2002; Kerstjens \& Nery, 2000; Light, Xu, \& Mossop, 1987; Stoynoff, 1997; Woodrow, 2006). What's more, an examination of international and domestic students at an Australian university reported weaker academic performance from international students, but this difference disappeared when language ability was taken into account (Ramburuth, 2001). This finding suggests that international students and domestic students have equally strong academic skills, but a lack of language skills impedes international student academic performance. Reading skills were commonly found to be the most important facet of proficiency in predicting academic success (Bayliss \& Raymond, 2004; Phakiti, 2008), but other investigations identified writing as the most predictive proficiency feature of academic success (Ramburuth, 2001; Li, Chen, \& Duanmu, 2010).

Despite consistent conclusions that proficiency and academic success are indeed linked, the correlation appears to be moderate. For instance, Phakiti (2008) showed that overall English proficiency accounted for only 7 percent of academic achievement, with reading proficiency holding an only slightly stronger hand at 10 percent. Furthermore, although Oliver, Vanderford, and Grote (2012) revealed that reading, listening, and speaking skills were significantly correlated with success for postgraduates, only reading proficiency was significantly related to GPA for undergraduates.

A closer analysis of study participants presents a rationale for these patchy findings. Nearly all of the studies examined used TOEFL or IELTS scores as the measure of proficiency. Before ELL students can begin university study in an English setting, they must have attained a minimum level of proficiency, i.e. a minimum score on the TOEFL or IELTS. Therefore, the investigations of ELLs' academic success looked only at students 
who had already demonstrated linguistic performance above a baseline deemed necessary for success. With this thought in mind, Stoynoff (1997) risked extrapolation complications to predict that the proficiency-success correlation, corrected for a restricted range of TOEFL scores, would be .39. Vinke and Jochems (1993), in an examination of NNES Indonesian engineering students, found the correlation to be .51. What's more, the proficiency-success correlation for engineers at the lowest proficiency level (TOEFL scores below 450) was nearly zero, while at the same time, proficiency was, predictably, not an impediment to students with very high linguistic competence. This pattern suggests that there is a range of linguistic skill in which an increase in proficiency increases the chance of academic success. The academic performance of students above that range is not substantially affected by increased proficiency; likewise, the success of students below that range is not improved with increased proficiency until the lower limit of the linguistic threshold is crossed (Vinke \& Jochems, 1993). Determining the cutoff points for the proficiency-success connection is a job in and of itself. The task lends direction to future investigations, as the range may vary according to a number of factors, including academic discipline.

In further support of the relationship between language proficiency and academic success, several studies established that proficiency more strongly predicts success for graduate students than undergraduates (Berman \& Cheng, 2001; Oliver, Vanderford, \& Grote, 2012). Mathews (2007) posited that research using undergraduate participants weakens the correlation between language skill and academic achievement because, at the undergraduate level, NNES and native English speakers go through a period of academic transition in which field-specific terminology must be acquired: "At the undergraduate level, one is allowed to be at a transitory stage because this is a psychological experience shared by North Americans and non-North Americans alike" (Mathews, 2007, p. 659). Due to this shared linguistic and personal metamorphosis, learning in an L2 has less of an effect on undergraduates than on graduate students, who are expected to already be well-versed in the jargon of their chosen profession and academia in general.

Another snag in solving the proficiency-success puzzle lies in the use of standardized test scores, most commonly TOEFL or IELTS scores, as proficiency determinants. The question of whether these exams do indeed accurately measure language proficiency is not new. Evidence regarding their validity and reliability has been provided in both the negative (Roemer, 2002) and the affirmative (Wainer \& Lukhele, 1997). However, Oliver et al. (2012) discovered that, at an Australian university, standardized tests such as the TOEFL, rather than in-house proficiency tests or previous class grades, provided the best evidence for students' potential academic success.

Still other factors muddle the dissection of the proficiency-success relationship. Logically, different levels of and kinds of linguistic skills are required for different academic fields of study. In addition, variations in cultural and linguistic background may be a confounding factor in proficiency and academic success measurements, although several studies have shown the contrary. For example, Nelson, Nelson, \& Malone (2004) were by and large unable to discern any distinctions in academic performance among cultural and linguistic groups. Furthermore, Bayliss and Raymond’s (2004) examination of L1 English-L2 French and L1 Chinese-L2 English university students found that L2 proficiency, especially reading skills, correlated with academic success for both groups.

In light of the abundance of complications in addressing language proficiency and academic achievement, it is useful to examine self-reports of NNES students engaging in study at English-speaking universities. Perhaps it 
is not surprising that the language task denoted as "most difficult" differed across studies, considering participants in these studies varied in culture, native language, degree progress, age, and major, to name only a few variables. Nevertheless, student insight is valuable in attempting to pinpoint which skills, both generally and specifically, generate the most problems for language learners.

The volume of reading required in academic study was denoted the largest difficulty by Chinese-speaking ELLs in a Canadian university MBA program (Bayliss \& Raymond, 2004). Although East Asian graduate students in Ren, Bryan, Min, and Wei’s (2007) investigation felt well-prepared by their previous English educational experiences for the reading demands at an American university, graduate students at a Canadian university explained that the difficulty of reading itself was not the problem but rather the time consumed by the task; they felt, as non-native speakers, they were much slower at completing reading assignments than their nativespeaking counterparts (Cheng, Myles, \& Curtis, 2004).

Alternatively, writing was also identified as a problematic area for both undergraduate and graduate ELLs. Studies have shown students to struggle with tasks such as understanding a writer's purpose (Berman \& Cheng, 2001), writing short reports (Cheng, Myles, \& Curtis, 2004), and adopting referencing customs (Dooey, 2010).

Listening was also a contender for most difficult skill. Vocabulary gaps presented some problems for students, but most were more greatly hindered by lack of comprehension at the extended discourse level (Ren et al., 2007). Specifically, students estimated that in their first year of English immersion study, they understood only 20 to 30 percent of lecture content (Johnson, 2008).

Finally, speaking also proved to be stressful for many international students. Participating in whole-class and group discussions, raising questions during class, and making oral presentations were pegged as especially difficult (Berman \& Cheng, 2001; Cheng, Myles, \& Curtis, 2004; Ren et al., 2007; Kim, 2006). Interestingly, East Asian graduate students designated making formal oral presentations as the most important speaking skill but reported class discussions and asking questions to be far more frequent tasks in American university classrooms (Kim, 2006). International students preferred hands-on tasks to discourse-based learning because they felt they could establish rapport with domestic students who, in spoken interactions, sometimes viewed ELL students as less competent (Parks \& Raymond, 2004; Ren et al., 2007). This finding is reflected in reports of international students lacking confidence, fearing mistakes, and feeling self-conscious while performing linguistic tasks (Dooey, 2010; Ren et al., 2007; Tompson \& Tompson, 1996). More than the obvious consternation that international students are viewed as deficient by their domestic peers, this finding is also disconcerting because language-learning strategies associated with risk-taking, such as interacting with native speakers and using hypothesized synonyms for forgotten terms, are linked to academic success (Rochecouste, Oliver, \& Mulligan, 2012).

Overall, research points toward the existence of a moderate but significant association between language proficiency and academic success. A multiplicity of factors, including but not limited to academic stage of the student, area of study, affective characteristics, cognitive skills, and educational, cultural, and linguistic background, may interact with and moderate the relationship. Although some evidence suggests a stronger correlation between language and study success, the modest relationship observed in the majority of research highlights the importance of non-linguistic factors in determining academic success. 


\section{Non-linguistic Factors in Academic Success}

Exploring the non-linguistic factors involved in academic success makes the experiences of domestic students as well as international students relevant to inspection. On the whole, students who feel at home, feel wellconnected to fellow students and teachers, and take part in extracurricular activities are more likely to graduate (Severiens \& Wolff, 2008). Furthermore, social support from family and friends has been shown to have a positive influence on study success of first-year students (Wilcox, Winn, \& Fyvie-Gauld, 2005). Based on the assumption that international students are far from home and often must bridge a language and culture gap to establish relationships with fellow students and faculty, ELLs seem to be at a disadvantage from the outset of their English education experiences. Fortunately, George, Dixon, Stansal, Lund Gelb, and Pheri (2008) identified a number of qualities and habits linked to academic success in Canadian university undergraduates that are equally attainable by both domestic and international students. Specifically, the greatest predictors of academic success were clearly defined goals, time management, spending less time in passive leisure, a healthy diet, waking up early, computer ownership, and spending less time sleeping. In fact, strong time management was an even better predictor of GPA than SAT scores. Moore (1994), too, showed a positive association between time management skills and academic success that was independent of academic aptitude as predicted by SAT scores.

An analysis of Dutch university students (Van Den Berg \& Hofman, 2005) lends greater insight into the contributors to academic success. Results revealed that students who had obtained a study grant made more progress toward degree completion than those without grants; women and majority ethnicities also earned more credits in an academic year, as did students with prior educational experiences. Education level of parents and socioeconomic status had no bearing on success in this context, and jobholding did not negatively influence study progress unless students committed more than 12 hours per week to work (Van Den Berg \& Hofman, 2005). Emotional and cognitive processes have also been shown to play a role in academic success. Not surprisingly, persistence and engagement in reflective and critical thinking showed positive effects on academic performance, while students who viewed learning as an exercise in memorization and facts recall had less success in a Spanish university setting (Phan, 2009).

The effects of age on academic achievement are mixed. McInnis, James, and McNaught (1995) determined that mature students perform better than younger students, but Clark and Ramsay (1990), Vinke and Jochems (1993), and Van Den Berg and Hofman (2005) found a negative relationship between age and success. These inconsistent conclusions can be explained by the interaction of age with other factors linked to low academic success, such as delayed educational careers and breaks in study (Van Den Berg \& Hofman, 2005).

With a grasp of the traits that contribute to student academic success on the whole, the next step is to home in on international student experiences. Upon arrival at university, both domestic and international students must adapt to a new setting. International students, however, must frequently make changes at a much deeper level and in many more facets of their lives than their domestic counterparts. The degree of comfort international students feel with the often unfamiliar aspects of their host environment defines their adjustment level (Black \& Gregersen, 1991; Snow Andrade, 2006). Language is by no means unrelated to student adjustment; students with higher TOEFL scores were observed as having fewer difficulties adjusting to the academic demands of English settings (Senyshyn, Warford, \& Zhan, 2000). Yet ELLs' abilities to adjust positively to the new demands placed on them beyond "mere" linguistic obstacles contribute in large part to their academic success. 
In a broad sense, there are two realizations of international student adjustment: assimilation, occurring when a minority student loses non-conforming characteristics and becomes indistinguishable from the dominant group, and acculturation, occurring when a student adapts to the dominant culture but at the same time maintains a sense of identity with the home culture (Castro-Abad, 1995). Because acculturation is viewed as the preferred outcome of the international student experience, adjustment will be equated with acculturation in this analysis.

Although previous lines of thought suggested cultural adjustment played out in a U pattern, with stages of initial excitement preceding culture shock and an eventual, gradual recovery, more data support the notion of adjustment as a linear process (Hechanova-Alampay, Beehr, Christiansen, \& Van Horn, 2002). Of course, cultural adjustment and culture shock varies by individual due to factors such as motivation, personality, previous experiences, pre-arrival preparation, interaction strategies, and home-host cultural similarity. The most common causes of stress in adjustment include cultural distance, language problems, unfamiliar academic demands, loneliness, and homesickness (Brown \& Holloway, 2008). Differences in motivation, self-efficacy, self-regulation strategies, attitudes toward difficulty, and transferability of former learning experiences to new situations have also been tied to academic performance regardless of language proficiency (Phakiti \& Li, 2011). In a cross-institutional comparison of nearly 1,000 business students in the Netherlands, Reinties et al. (2012) determined GPA after the first year of study was correlated with academic adjustment, personal-emotional adjustment, commitment to educational-institutional goals, and perception of faculty.

Rienties et al. (2012) classified these facets of adjustment into two categories: academic and social integration. Academic integration describes adjustment to the educational demands of the new setting, how well a student deals with the interpersonal requirements of study (e.g. working in groups), personal and emotional distress experienced while adapting to the local way of life, and degree of commitment to educational-institutional goals. Social integration pertains to the social way of life at the university, including a student's perception of faculty reputation, social support systems, social life, ethnic background, and financial support. Rienties' team affirmed that academic performance was primarily affected by academic integration but that features of social integration, namely having friends from both the home and host culture, sharing accommodation, and being a member of an association or club, also contributed to academic success.

Academic integration. Although our previous discussion summarized the importance of linguistic expertise to academic success, it should not be overshadowed by the challenge of integrating into a new academic culture. Fox (1994) discovered that what professors perceived to be an inability to analyze and develop a written argument was in fact a result of cultural differences in communication styles, not language proficiency. Examining Westerners and non-Westerners studying Chinese as a foreign language in China, Yu and Downing (2012) discerned that socio-cultural adaptation was influenced more by integrative motivation and less by L2 proficiency. That is, internal motivators such as interest in the language and culture rather than external, environmental motivators such as job acquisition pressures fostered better adjustment. The significance of internal versus environmental motivation to international student adjustment was echoed in research by Kagan and Cohen (1990).

Other affective factors have been linked to academic integration and, in turn, academic success, self-efficacy being a principle one. Self-efficacy refers to a person's confidence in his/her ability to accomplish tasks (Bandura, 1986). In terms of academic adjustment, individuals with high self-efficacy are typically more willing to learn new behaviors and persist in exhibiting those behaviors, thereby gaining more opportunities for 
feedback (Black \& Gregersen, 1991). Self-efficacy has also been shown to relate negatively to strain (Hechanova-Alampay et al., 2002) and positively to adjustment and grades (Hechanova-Alampay et al., 2002; McKenzie \& Schweitzer, 2001). Self-efficacy's role in fostering student success is not limited to academic integration, though; self-efficacy and its affective products play a large part in social adjustment, as well.

Social integration. Research has shown that self-efficacy in social situations contributes to self-esteem in general (Sherer, Maddux, Mercandante, Prentice-Dunn, Jacobs, \& Rogers, 1982). In turn, higher levels of selfesteem are associated with international student acculturation (Al-Sharideh \& Goe, 1998). Either fortunately or unfortunately, self-esteem represents a dynamic attribute that changes across situations (Mruk, 1995). This quality can be detrimental to international students, as many international students experience a loss of social status when the status they enjoyed at home is not recognized in their new environment. This stripping of one's accustomed social standing, compounded by unfamiliar customs that reduce students' competency in meeting social and personal needs, results in lowered self-esteem in many international students, and, in turn, lowered acculturation.

Founding their research on these interactions, Al-Sharideh and Goe (1998) scrutinized the effect of social factors on the personal adjustment of international students at an American university. They found that having strong ties to compatriots had a positive effect on self-esteem and weakened the tie between self-esteem and acculturation. That is, participation in ethnic communities within a larger host community seemed to buffer the influence of acculturation on self-esteem. However, striking a balance between home and host culture appeared to be crucial; students who demonstrated extensive and exclusive integration into an ethnic community with minimal participation in the host culture showed a negative pattern in self-esteem. Importantly, ties to Americans independently promoted self-esteem regardless of relationships with coculturals. Therefore, it can be concluded that international students require support from both compatriots and the host culture to achieve maximum acculturation and, thus, academic success, a conclusion reproduced in other research (Li et al., 2010; Rochecouste et al., 2012). Wilcox et al. (2005) also supported this notion in part, observing that study support and social support by family and friends was influential to first-year student academic success, although students who perceived high pressure from their families to succeed academically experienced adverse academic effects. It is also noteworthy that, although social integration is generally perceived as a positive step toward cultural adjustment and, hence, academic success, social adjustment was actually found to have a negative relationship with study performance in one instance; non-Western students in the Netherlands who were more socially adjusted and actively participated in student life were less likely to get good grades (Rienties et al., 2012). Perhaps one Taiwanese doctoral student best rationalized this outlying finding: "If I had to read every book assigned by my professors... and write [assignments] which would only take native-Englishspeaking students two days but take me five...I would need a lot of time...As for having a good time [with friends], well, just forget it!” (Chang \& Kanno, 2010, p. 685).

In general, investigations into both the academic and social integration of international students do much to inform educators of the non-linguistic factors associated with academic success. However, these studies also pose a danger because many of them lump "international students" into one block. At most, a clumsy distinction is made between Western and Asian mentalities, with no regard to the ethnic, cultural, and national differences making up those groups and little attention given to students who belong to neither group. Among studies that did differentiate international student ethnicities, Hechanova-Alampay et al. (2002) found the link between 
cultural novelty and adjustment to be non-significant; still, most studies generally support the notion that Western European ELLs adjust more easily to English, American, Canadian, and Australian cultures than do Asian ELLs (Rienties et al., 2012; Senyshyn et al., 2000).

\section{Conclusion}

In summary, achieving success in an L2 academic setting demands far more than linguistic competence and subject knowledge. Adapting to a novel learning style and a foreign way of life outside the school setting weighs heavily on international students' performance. This process requires change at the deepest psychological and personal levels, as recounted by a Chinese student in the UK: "I don't think I have ever cried in China. But I don’t know how many times I have cried here” (Gu \& Schweisfurth, 2006, p. 83). Yet, once students become successful in negotiating their adopted locales, they achieve a newfound sense of selfresponsibility, independence, and achievement in managing their study progress and, also, their life's path (Gu \& Schweisfurth, 2006). For the sake of transforming both native and nonnative students into global citizens, then, universities must chart a course for facilitating the linguistic acquisition and cultural adjustment of their international scholars. 


\section{References}

Abu-Akel, A. (1997). On reading-writing relationships in first and foreign languages. JALT Journal, 19, 198216.

Al-Sharideh, K. A., \& Goe, W. R. (1998). Ethnic communities within the university: An examination of factors influencing the personal adjustment of international students. Research in Higher Education, 39(6), 699725.

American Council on the Teaching of Foreign Languages (ACTFL). (2012). ACTFL Proficiency Guidelines 2012. Retrieved from http://www.actfl.org/sites/default/files/pdfs/public/ACTFLProficiencyGuidelines2012_FINAL.pdf.

Ayers, J. B., \& Peters, M. R. (1977). Predictive validity of the test of English as a foreign language for Asian graduate students in engineering, chemistry, or mathematics. Educational and Psychological Measurement, 37(2), 461-463.

Bachman, L. F. (1990). Fundamental considerations in language testing. Oxford: Oxford University Press.

Bachman, L. F. (1991). What does language testing have to offer? TESOL Quarterly, 25(4), 671-704.

Bailey, N., Madden, C., \& Krashen, S. (1974). Is there a 'natural sequence' in adult second language learning? Language Learning, 24, 235-243.

Bandura, A. (1986). Social Learning Theory. Englewood Cliffs, NJ: Prentice-Hall, Inc.

Bayliss, D., \& Raymond, P. M. (2004). The link between academic success and L2 proficiency in the context of two professional programs. The Canadian Modern Language Review, 61(1), 29-51.

Berman, R., \& Cheng, L. (2001). English academic language skills: Perceived difficulties by undergraduate and graduate students, ad their academic achievement. Canadian Journal of Applied Linguistics, 4, 25-40.

Black, J. S., \& Gregersen, H. B. (1991). Antecedents to cross-cultural adjustment for expatriates in Pacific Rim assignments. Human Relations, 44, 497-515.

Brown, L., \& Holloway, I. (2008). The adjustment journey of international postgraduate students at an English university. Journal of Research in International Education, 7, 232-249.

Canale, M., \& Swain, M. (1980). Theoretical bases of communicative approaches to second language teaching and testing. Applied Linguistics, 1(1), 1-47.

Carroll, J. B. (1967). On sampling from a lognormal model of word frequency distribution. In H. Kucera \& W. N. Francis (Eds.), Computational analysis of present-day American English (pp. 406-424). Providence: RI: Brown University.

Carroll, J., \& Sapon, S. (2000). Modern Language Aptitude Test (MLAT): Manual. San Antonio, TX: Psychological Corp. Republished by Second Language Testing, Inc., http://www.2LTI.com.

Carson, J. E., Carrell, P. L., Silberstein, S., Kroll, B., \& Kuehn, P. A. (1990). Reading-writing relationships in first and second language. TESOL Quarterly, 24, 245-266. 
Castro-Abad, C. (1995). A human development workshop on cultural identity for international students. Princeton, NJ. Princeton University, Mid-Career Fellowships Program. Available: ERIC Document Reproduction Service No. Ed 384382.

Chang, Y.-J., \& Kanno, Y. (2010). NNES doctoral students in English-speaking academe: The nexus between language and discipline. Applied Linguistics, 31(5), 671-692.

Chapelle, C. (1998). Construct definition and validity inquiry in SLA research. In L. F. Bachman \& A. D. Cohen, (Eds.), Interfaces between second language acquisition and language testing research. Cambridge: Cambridge University Press, 32-70.

Cheng, L., Myles, J., \& Curtis, A. (2004). Targeting language support for non-native English-speaking graduate students at a Canadian university. TESL Canada Journal, 21(2), 50-71.

Clark, E. E., \& Ramsay, W. (1990). Problems of retention in tertiary education. Education Research and Perspectives, 17, 47-57.

Crossley, S. A., \& McNamara, D. S. (2012). Predicting second language writing proficiency: the roles of cohesion and linguistic sophistication. Journal of Research in Reading, 35(2), 115-135.

Crossley, S. A., Salsbury, T., \& McNamara, D. S. (2011). Predicting the proficiency level of language learners using lexical indices. Language Testing, 29(2), 243-263.

Cummins, J. (1980). The crosslingual dimensions of language proficiency: Implications for bilingual education and the optimal age issue. TESOL Quarterly, 14, 175-187.

De Jong, J. H. A. L. (2004, February). Comparing the psycholinguistic and the communicative paradigm of language proficiency. Paper presented at the International Workshop of Psycholinguistic and Psychometric Aspects of Language Assessment in the Common European Framework of Reference for Languages, University of Amsterdam, The Netherlands.

De Jong, N. H., Steinel, M. P., Florijn, A. F., Schoonen, R., \& Hulstijn, J. H. (2012). Facets of speaking proficiency. Studies in Second Language Acquisition, 34, 5-34.

Dooey, P. (2010). Students’ perspectives of an EAP pathway program. Journal of English for Academic Purposes, 9, 184-197.

Dooey, P., \& Oliver, R. (2002). An investigation into the predictive validity of the IELTS test as an indicator of future academic success. Prospect, 17(1), 36-54.

Educational Testing Service. (2004). iBT/Next Generation TOEFL Test: Independent speaking rubrics (scoring standards). Retrieved from http://www.ets.org/Media/Tests/TOEFL/pdf/Speaking_Rubrics.pdf.

Feast, V. (2002). The impact of IELTS scores on performance at university. International Education Journal, 3(4), 70-85.

Fox, H. (1994). Listening to the world: Cultural issues in academic writing. Urbana, IL: National Council of Teachers of English. 
Ganschow, L., Sparks, R., Anderson, R., Javorsky, J., Skinner, S., \& Patton, J. (1994). Differences in anxiety and language performance among high, average, and low anxious college foreign language learners. Modern Language Journal, 78, 41-55.

Garcia Gomez, P., Noah, A., Schedl, M., Wright, C., \& Yolkut, A. (2007). Proficiency descriptors based on a scale-anchoring study of the new TOEFL iBT reading test. Language Testing, 24(3), 417-444.

Graham, J. C. (1987). English language proficiency and the prediction of academic success. TESOL Quarterly, 21(3), 505-521.

George, D., Dixon, S., Stansal, E., Lund Gelb, S., \& Pheri, T. (2008). Time diary and questionnaire assessment of factors associated with academic and personal success among university undergraduates. Journal of American College Health, 56(6), 706-715.

Gu, Q., \& Schweisfurth, M. (2006). Who adapts? Beyond Cultural Models of 'the' Chinese learner. Language, Culture, and Curriculum, 19(1), 74-89.

Harley, R., \& Hart, D. (2002). Age, aptitude, and second language learning on a bilingual exchange. In P. Robinson (Ed.), Individual differences and instructed language learning (pp. 301-330). Amsterdam: Benjamins.

Harper, R., Prentice, S., \& Wilson, K. (2011). English language perplexity: Articulating the tensions in the DEEWR “Good Practice Principles.” The International Journal of the First Year in Higher Education, 2(1), 36-48.

Hawkins, R. (2001). Second language syntax: A generative introduction. Malden, MA: Blackwell.

Hechanova-Alampay, R., Beehr, T. A., Christiansen, N. D., \& Van Horn, R. K. (2002). School Psychology International, 23, 458-474.

Henriksen, B. (1999). Three dimensions of vocabulary development. Studies in Second Language Acquisition, 21, 303-17.

Higgs, T. V., \& Clifford, R. (1982). The push toward communication. In T. V. Higgs (Ed.), Curriculum, competence and the foreign language teacher (pp. 243-265). Skokie, IL: National Textbook Company.

Hulstijn, J. H. (2007). The shaky ground beneath the CEFR: Quantitative and qualitative dimensions of language proficiency. The Modern Language Journal, 91(4), 663-667.

IELTS Partners. (2009). IELTS writing task 1: Band descriptors (public version). Retrieved from http://www.ielts.org/PDF/Writing\%20Band\%20descriptors\%20Task\%201.pdf.

Isaacs, T., \& Tromfimovich, P. (2012). Deconstructing comprehensibility: Identifying the linguistic influences on listeners’ L2 comprehensibility ratings. Studies in Second Language Acquisition, 34, 475-505.

Isonio, S. (1994). Retention and success rates by course category, year, and selected student characteristics at Golden West College. Huntington Beach, CA: Golden West College. ERIC Document Reproduction Service No. ED 377895. 
Ito, Fumihiko. (2004). The interrelationship among first language writing skills, second language writing skills, and second language proficiency of EFL university students. The Japan Association of College English Teachers Bulletin, 39, 43-58.

Iwashita, N., Brown, A., McNamara, T., \& O’Hagan, S. (2008). Assessed levels of second language speaking proficiency: How distinct? Applied Linguistics, 29, 24-49.

Johnson, E. M. (2008). An investigation into pedagogical challenges facing international tertiary-level students in New Zealand. Higher Education Research \& Development, 27(3), 231-243.

Kagan, H., \& Cohen, J. (1990). Cultural adjustment of international students. Psychological Science, 1(2), 133137.

Kerstjens, M., \& Nery, C. (2000). Predictive validity in the IELTS test: A study of relationships between IELTS scores and students' subsequent academic performance. English Language Testing System Research Reports, 3, 85-108.

Kim, S. (2006). Academic oral communication needs of East Asian international graduate students in nonscience and non-engineering fields. English for Specific Purposes, 25, 479-489.

Lantolf, J. P., \& Frawley, W. (1988). Proficiency: Understanding the construct. Studies in Second Language Acquisition, 10, 181-195.

Levis, J. M. (2006). Pronunciation and the assessment of spoken language. In R. Hughes (Ed.), Spoken English, TESOL and applied linguistics: Challenges for theory and practice (pp. 245-270). New York: Palgrave Macmillan.

Li, G., Chen, W., \& Duanmu, J.-L. (2010). Determinants of international students’ academic performance: A comparison between Chinese and other international students. Journal of Studies in International Education, 14, 389-405.

Light, R. L., Xu, M., \& Mossop, J. (1987). English proficiency and academic performance of international students. TESOL Quarterly, 21(2), 251-261.

Llosa, L. (2011). Standards-based classroom assessments of English proficiency: A review of issues, current developments, and future directions for research. Language Testing, 28(3), 367-382.

Long, M. H., Gor, K., \& Jackson, S. (2012). Linguistic correlates of second language proficiency. Studies in Second Language Acquisition, 34, 99-126.

MacIntyre, P. (2002). Motivation, anxiety, and emotion in second language acquisition. In R. Robinson (Ed.), Individual differences and instructed language learning (pp. 45-68). Amsterdam: Benjamins.

Macken-Horarik, M., Devereux, L., Trimingham-Jack, C., \& Wilson, K. (2006). Negotiating the territory of tertiary literacies: A case study of teacher education. Linguistics and Education, 17(3), 240-257.

Masgoret, A.-M., Gardner, R. C. (2003). Attitudes, motivation, and second language learning: A meta-analysis of studies conducted by Gardner and associates. Language Learning, 53(1), 123-163. 
Mathews, J. (2007). Predicting international students’ academic success...may not always be enough: Assessing Turkey’s Foreign Study Scholarship Program. Higher Education, 53, 645-673.

McInnis, C., James, R., \& McNaught, C. (1995). First year on campus: Diversity in the initial experiences of Australia undergraduates. Melbourne: University of Melbourne Press.

McKenzie, K., \& Schweitzer, R. (2001). Who succeeds at university? Factors predicting academic performance in first year Australian university students. Higher Education Research and Development, 20, 21-33.

Moore, P. (1994). The influence of time management practices and perceptions on academic performance. Dissertation Abstracts International, 55(7-B), 3051.

Mori, S. (2000). Addressing the mental health concerns of international students. Journal of Counseling and Development, 78, 137-144.

Mruk, C. (1995). Self-esteem: Research, theory, and practice. New York: Springer.

Murray, N. L. (2010). Conceptualising the English language needs of first year university students. The International Journal of the First Year in Higher Education, 1(1), 55-64.

Nation, I. S. P. (2001). Learning vocabulary in another language. New York: Cambridge University Press.Neal,

M. E. (1998). The predictive validity of the GRE and TOEFL exams with GGPA as the criterion of graduate success for international graduate students in science and engineering. ERIC Document Reproduction Service No. ED424294,

Nelson, C. V., Nelson, J. S., \& Malone, B. G. (2004). Predicting success of international graduate students in an American university. College and University, 80(1), 19-27.

Northedge, A. (2003). Enabling participation in academic discourse. Teaching in Higher Education, 8(2), 169180.

Oliver, R., Vanderford, S., \& Grote, E. (2012). Evidence of English language proficiency and academic achievement of non-English-speaking background students. Higher Education Research \& Development, 31(4), 541-555.

Parks, S., \& Raymond, P. M. (2004). Strategy use by nonnative-English-speaking students in an MBA program: Not business as usual! Modern Language Journal, 88(3), 374-389.

Person, N. E. (2002). Assessment of TOEFL scores and ESL classes as criteria for admission to career \& technical education and other selected Marshall University graduate programs. Presented at the 76th Annual Meeting of the Association for Career and Technical Education. (ERIC Document Reproductive Service No. ED473756).

Phakiti, A. (2008). Predicting NESB international postgraduate students’ academic achievement: A structural equation modeling approach. International Journal of Applied Educational Studies, 3(1), 18-39.

Phakiti, A., \& Li, L. (2011). General academic difficulties and reading and writing difficulties among Asian ESL postgraduate students in TESOL at an Australian university. RELC Journal, 42(3), 227-264. 
Phan, H. P. (2009). Reflective thinking, effort, persistence, disorganization, and academic performance: A mediational approach. Electronic Journal of Research in Educational Psychology, 7(19), 927-952.

Pienemann, M. (1998). Language processing and second language development: Processability theory. Amsterdam: Benjamins.

Pienemann, M. (2005). Discussing PT. In M. Pienemann (Ed.), Cross-linguistic aspects of processability theory (pp. 61-83). Amsterdam: Benjamins.

Qian, D. D., \& Schedl, M. (2004). Evaluation of an in-depth vocabulary knowledge measure for assessing reading performance. Language Testing, 21(1), 28-52.

Ramburuth, P. (2001). Language diversity and the first-year experience: Implications for academic achievement and language skills acquisition. Journal of the First-Year Experience, 13(2), 75-93.

Ren, J., Bryan, K., Min, Y., \& Wei, Y. (2007). Language preparation and the first year experience: What administrators and policy makers should know. Florida Journal of Educational Administration \& Policy, 1(1), 11-24.

Rienties, B., Beausaert, S., Grohnert, T., Niemantsverdriet, S., \& Kommers, P. (2012). Understanding academic performance of international students: The role of ethnicity, academic and social integration. Higher Education, 63, 685-700.

Rochecouste, J., Oliver, R., \& Mulligan, D. (2012). English language growth after university entry. International Journal of Educational Research, 53, 1-8.

Roemer, A. (2002). A more valid alternative to TOEFL? College and University, 77(4), 13-17.

Rysiewicz, J. (2008). Cognitive profiles of (un)successful FL learners: A cluster analytical study. Modern Language Journal, 92, 87-99.

Selvadurai, R. (1998). Problems faced by international students in American colleges and universities. Community Review, 16, 153-158.

Senyshyn, R. M., Warford, M. K., \& Zhan, J. (2000). Issues of adjustment to higher education: International students’ perspectives. International Education, 30(1), 17-35.

Severiens, S., \& Wolff, R. (2008). A comparison of ethnic minority and majority students: Social and academic integration, and quality of learning. Studies in Higher Education, 33, 253-266.

Sherer, M, Maddux, J. E., Mercandante, B., Prentice-Dunn, S., Jacobs, B., \& Rogers, R. W. (1982). The selfefficacy scale: Construction and validation. Psychological Reports, 51, 663-671.

Snow Andrade, M. (2006). International students in English-speaking universities. Journal of Research in International Education, 5, 131-154.

Song, M. Y. (2008). Do divisible subskills exist in second language (L2) comprehension? A structural equation modeling approach. Language Testing, 25(4), 435-464. 
Song, M. Y. (2011). Note-taking quality and performance on an L2 academic listening test. Language Testing, 29(1), 67-89.

Sparks, R. L., \& Ganschow, L. (1991). Foreign language learning difficulties: Affective or native language aptitude differences? Modern Language Journal, 75, 3-16.

Sparks, R. L., \& Ganschow, L. (1995). A strong inference approach to causal factors in foreign language learning: A response to MacIntyre. Modern Language Journal, 79, 235-244.

Sparks, R. L., \& Ganschow, L. (1996). Teachers’ perceptions of students’ foreign language skills and affective characteristics. Journal of Educational Research, 89, 172-185.

Sparks, R. L., Artizer, M., Ganschow, L., Siebenhar, D., Plageman, M., \& Patton, J. (1998). Differences in native-language skills, foreign-language aptitude, and foreign-language grades among high-, average-, and low-proficiency foreign-language learners: two studies. Language Testing, 15(2), 181-216.

Sparks, R. L., Humbach, N., \& Javorsky, J. (2008). Comparing high and low achieving, LD, and ADHD foreign language learners: Individual and longitudinal differences. Learning and Individual Differences, 18, 2943.

Sparks, R. L., Patton, J., \& Ganschow, L. (2012). Profiles of more and less successful L2 learners: A cluster analysis study. Learning and Individual Differences, 22, 463-472.

Sparks, R. L., Patton, J., Ganschow, L., \& Humbach, N. (2009). Long-term cross-linguistic transfer of skills from L1 to L2. Language Learning, 59, 203-243.

Sparks, R. L., Patton, J., Ganschow, L., \& Humbach, N. (2011). Subcomponents of second-language aptitude and second-language proficiency. Modern Language Journal, 95, 253-273.

Sparks, R. L., Patton, J., Ganschow, L., Humbach, N., \& Javorsky, J. (2006). Native language predictors of foreign language proficiency and foreign language aptitude. Annals of Dyslexia, 56, 129-160.

Spinner, P. (2011). Second language assessment and morphosyntactic development. Studies in Second Language Acquisition, 33, 529-561.

Stoynoff, S. (1997). Factors associated with international students' academic achievement. Journal of Instructional Psychology, 24(1), 56-69.

Taylor, L., \& Geranpayeh, A. (2011). Assessing listening for academic purposes: Defining and operationalising the test construct. Journal of English for Academic Purposes, 10, 89-101.

Tompson, H. B., \& Tompson, G. H. (1996). Confronting diversity issues in the classroom with strategies to improve satisfaction and retention of international students. Journal of Education for Business, 72(1), 53-57.

Usó-Juan, E. (2006). The compensatory nature of discipline-related knowledge and English-language proficiency in reading English for academic purposes. Modern Language Journal, 90(2), 210-227. 
Van Den Berg, M. N., \& Hofman, W. H. A. (2005). Student success in university education: A multimeasurement study of the impact of student and faculty factors on study progress. Higher Education, 50, 413-446.

Vainikka, A., \& Young-Scholten, M. (2006). The roots of syntax and how they grow: Organic grammar, the basic variety, and processability theory. In S. Unsworth, T. Parodi, A. Sorace, \& M. Young-Scholten (Eds.), Paths of development in L1 and L2 acquisition (pp. 77-106). Amsterdam: Benjamins.

Vinke, A.A., \& Jochems, W. M. G. (1993). English proficiency and academic success in international postgraduate education. Higher Education, 26(3), 275-285.

Wainer, H., \& Lukhele, R. (1997). How reliable are TOEFL scores? Educational and Psychological Measurement, 57(5), 741-758.

Wilcox, P., Winn, S., \& Fyvie-Gauld, M. (2005). It was nothing to do with the university, it was just the people: The role of social support in the first-year experience of higher education. Studies in Higher Education, 30(6), 707-722.

Wolfe-Quintero, K., Inagaki, S., \& Kim, H. Y. (1998). Second language development in writing: Measures of fluency, accuracy, \& complexity. Honolulu, HI: University of Hawai i Press.

Woodrow, L. (2006). Academic success of international postgraduate education students and the role of English proficiency. University of Sydney Papers in TESOL, 1. (Paper 3, 51-70). As cited in Oliver, R., Vanderford, S., \& Grote, E. (2012). Evidence of English language proficiency and academic achievement of non-English-speaking background students. Higher Education Research \& Development, 31(4), 541-555.

Young-Scholten, M., \& Ijuin, C. (2006). How can we best measure adult ESL student progress? TESOL Adult Education Interest Section Newsletter, 4(2).

Yu, B., \& Downing, K. (2012). Determinants of international students' adaptation: Examining effects of integrative motivation, instrumental motivation and second language proficiency. Educational Studies, 38(4), 457-471.

Zareva, A., Schwanenflugel, P., \& Nikolova, Y. (2005). Relationship between lexical competence and language proficiency. Studies in Second Language Acquisition, 27, 567-595. 